\title{
Structural evolution of imidazolium-based poly (ionic liquid) assemblies during solvent evaporation
}

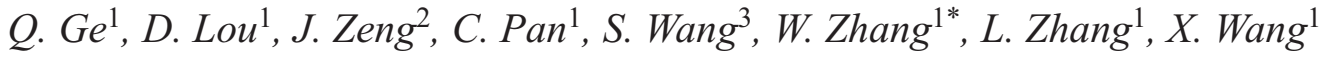 \\ ${ }^{1}$ Department of Chemistry, Key Laboratory of Advanced Textile Materials and Manufacturing Technology of Education \\ Ministry, Zhejiang Sci-Tech University, 310018 Hangzhou, China \\ ${ }^{2}$ Shanghai Synchrotron Radiation Facility, Zhang Heng Road, Pudong New District, 201203 Shanghai, China \\ ${ }^{3}$ Department of Physics, Zhejiang Sci-Tech University, 310018 Hangzhou, China
}

\begin{abstract}
Poly (ionic liquid)s (PILs) with a desirable tunability in their structures and properties have promising potentials to produce a hierarchically ordered functional materials. The structural evolution of imidazolium-based PILs with different counteranions during in-situ solvent evaporation has been investigated. Small angle X-ray scattering (SAXS) and X-ray diffraction studies indicate that upon solvent evaporation, poly $\left[\mathrm{C}_{16} \mathrm{VIm}^{+}\right]\left[\mathrm{Br}^{-}\right]$displays a weakly ordered lamellar morphology and finally a hexagonal perforated lamellar structure. Over a wide range of dimethyl formamide (DMF) content, however, the poly $\left[\mathrm{C}_{16} \mathrm{VIm}^{+}\right]\left[\mathrm{BF}_{4}^{-}\right] / \mathrm{DMF}$ mixture shows a lamellar structure with a tiny minority of bicontinuous cubic phase that disappears instead in the corresponding dried samples caused by the decrease in space-filling requirement for alkyl chains arrangement. For poly $\left[\mathrm{C}_{16} \mathrm{VIm}^{+}\right]\left[\mathrm{PF}_{6}{ }^{-}\right]$, there is almost no change in inner structures with solvent evaporation except a more ordered lamellar morphology observed in the dried sample. Notably, an interdigitated packing of alkyl tails dominates the lamellar sheets for all dried PIL samples. These results indicate that the design and fabrication of PIL assemblies with ordered structures can be achieved by simply changing counteranion and solvent content, which offers a feasible approach for engineering PIL-based nano-scale functional materials.
\end{abstract}

Keywords: nanomaterials, poly (ionic liquid)s, self-assembly, lamellar structure, solvent evaporation

\section{Introduction}

The fabrication of polymer-based assemblies with molecular packing at different length scales has recently received a great deal of attention due to their promising potentials to produce functional, nanostructured materials [1-5]. Amphiphilic block or graft copolymers are common candidates for such self-assembled organization and ordering in nano-, and mesoscale. This self-assembly behavior is normally driven by a variety of covalent interaction and noncovalent interactions (e.g., electrostatics, hydrogen bonding, and van der Waals interactions). In terms of morphology versatility, copolymers with amphiphilic characteristic can self-assemble into various struc- tures such as micelles, vesicles in their aqueous or organic solution, and lamellar, hexagonally packed cylinder, spherical, and gyroid structures in their solid bulk [6-11]. The size and morphology of these ordered structures are dependent on the composition, molecular weight, processing characteristics, especially on the balance between the hydrophobic domains and the hydrophilic domains.

Ionic liquids (ILs) have been paid increasingly attention because of their unique properties such as non-volatility, nonflammability, high thermal stability and tunable solvation interactions [12]. Those unique properties can be tuned by modifying the combination of cations and anions, displaying a 'designer

*Corresponding author, e-mail: zhwei@zstu.edu.cn

(C) BME-PT 
property' [13]. In particular, N-alkyl vinylimidazolium-based ILs exhibit typically amphiphilic characteristic as long alkyl groups are attached to the imidazolium cores. In their aggregates, for example, the alky tails form a hydrophobic domain, while the imidazolium headgroups form a hydrophilic region, which make them a desirable candidate for spatial organization and ordering [14, 15]. Like amphiphilic copolymers, IL homopolymers can also be utilized to fabricate nanostructrued functional materials by taking advantage of their self-assembly characteristics. It was well documented that $\mathrm{N}$-alkyl vinylimidazolium-based ILs with long alkyl groups can self-assemble into ordered liquid crystalline mesophases [1623]. In order to obtain a mechanically durable material, a polymerizable moiety, such as vinyl group, is normally introduced to IL molecules. Both IL monomers and the corresponding poly (ionic liquid)s (PILs) can form well-ordered mesophase structures when they are dispersed in water, but the exact morphologies between them seem to be different. For example, a binary mixture of 1-decyl-3-vinylimidazolium monomer and $15 \mathrm{wt} \%$ water was found to self-assemble into a 2-D hexagonal structured physical gel; Upon UV photopolymerization, the obtained selfsupporting chemical gel adopted a hexagonal perforated lamellar structure (HPL) featuring well-defined hydrophilic (pores) and hydrophobic regions [21]. On the other hand, when a photopolymerizable acryloyl functional group was attached to the alkyl chain terminus, the resulting IL monomer, 1-(10-(acryloyloxy)decyl)-3-methylimidazolium chloride $\left(\left[\mathrm{AcrC}_{10} \mathrm{mim}^{+}\right]\left[\mathrm{Cl}^{-}\right]\right)$, formed a well-ordered mesophase with tetragonal morphologies over a wide range of water content. However, a 3D bicontinuous cubic phases was observed in a binary mixture of poly $\left[\mathrm{AcrC}_{10} \mathrm{mim}^{+}\right]\left[\mathrm{Cl}^{-}\right]$with water [22]. In fact, water content and molecular architecture are generally used as means by which to tune the mesophase architectures of PIL-based functional materials.

Knowledge of a structural change of PILs during insitu solvent evaporation is of vital importance for the fabrication of PIL-based assemblies. Although the water-induced structural change in PIL mesophase is well established as mentioned above, few reports focus on the self-assembly of PILs themselves in organic solvents. In fact, investigation on the hierarchical packing of PILs in the organic media appears to be more important because PILs carrying different kinds of anion and cation are often soluble in organic solvents instead of water, and more specifically, the ordered PIL assemblies is often obtained from PIL/ organic solvent systems [23]. In this work, a series of poly (N-alkyl vinylimidazolium) with different counteranions, prepared by a simple radical solution polymerization, were dissolved in organic solvents to form homogenous solution. As the drying of the resultant PIL solution, synchrotron small angle X-ray scattering (SAXS) as well as X-ray diffraction (XRD) were employed for characterization in an effort to explore the structural evolution during in-situ solvent evaporation. The effect of anion and solvent content on the resulting PIL nano- and mesostructures was discussed in detail. This contribution provides a diverse strategy for tuning internal structures and morphologies of PIL-based functional materials.

\section{Experimental methods}

\subsection{Synthesis}

\subsubsection{Materials}

1-vinylimidazole (Aldrich, 99\%, CAS Number: 107263-5), 1- bromohexadecane (Aldrich, 99\%, CAS Number: 112-82-3), Azoisobutyronitrile (AIBN, Aldrich, 98\%, CAS Number: 78-67-1), bis(trifluoromethane) sulfonamide lithium salt (LiTf2N, Aladdin, 99\%, CAS Number: 90076-65-6), $\mathrm{NaBF}_{4}$ (Aladdin, 99\%, CAS Number: 13755-29-6), $\mathrm{KPF}_{6}$ (Aladdin, 99\%, CAS Number: 17084-13-6) were used as received. All reagents including acetone (CAS Number: 6764-1) n-propanol (n-PrOH, CAS Number: 71-23-8), chloroform (CAS Number: 67-66-3), ethyl acetate (CAS Number: 141-78-6), dimethylformamide (DMF, CAS Number: 68-12-2) and tetrahydrofuran (THF, CAS Number: 109-99-9) were of analytic grade, and were used without further purification.

\subsubsection{Synthesis of \\ 1-hexadecyl-3-vinylimidazolium bromide $\left(\left[\mathrm{C}_{16} \mathrm{VIm}^{+}\right]\left[\mathrm{Br}^{-}\right]\right)$}

Ionic Liquid monomers were synthesized as described in Figure 1. 1-vinylimidazole (0.1 mol, $9.41 \mathrm{~g})$, 1-bromohexadecane $(0.12 \mathrm{~mol}, 36.64 \mathrm{~g})$ were dissolved in $30 \mathrm{~mL}$ dried ethanol in a $150 \mathrm{~mL}$ flask. The reaction mixture was degassed under vacuum for $10 \mathrm{~min}$ and refilled with nitrogen. The flask was placed in pre-heated oil bath at $70^{\circ} \mathrm{C}$ for $24 \mathrm{~h}$. After reaction, the solution was cooled down to room temperature. The viscous liquid was precipitated into ethyl acetate, and then re-dissolved in ethanol. The dissolution-precipitation purification was repeated 


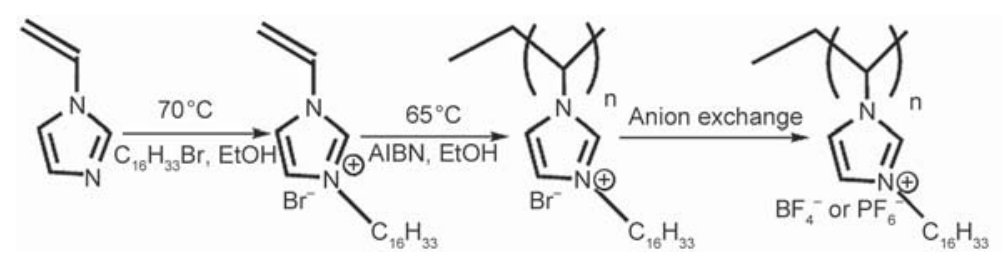

Figure 1. Synthesis of poly $\left[\mathrm{C}_{16} \mathrm{VIm}^{+}\right]\left[\mathrm{X}^{-}\right]\left(\mathrm{X}^{-}=\mathrm{Br}^{-}, \mathrm{BF}_{4}^{-}\right.$, and $\left.\mathrm{PF}_{6}^{-}\right)$

for three times. The resultant viscous liquid was further dried under vacuum at $40^{\circ} \mathrm{C}$ for $24 \mathrm{~h}$. The final product of 1-hexadecyl-3-vinylimidazolium bromide $\left(\left[\mathrm{C}_{16} \mathrm{VIm}^{+}\right]\left[\mathrm{Br}^{-}\right]\right)$was white power $(80 \%$ yield $)$. ${ }^{1} \mathrm{H}-\mathrm{NMR}$ [DMSO-d $\mathrm{d}_{6}, \delta$ ppm relative to TMS]: a 9.48 (s, 1H), b 8.20 (s, 1H), c 7.94 (s, 1H), f 7.30 (m, 1H), d $5.97(\mathrm{dd}, 1 \mathrm{H})$, e $5.44(\mathrm{dd}, 1 \mathrm{H}), \mathrm{g} 4.18(\mathrm{t}, 2 \mathrm{H}), \mathrm{h}$ $1.83(\mathrm{~d}, 2 \mathrm{H})$, i 1.24 (s, 26H), j $0.86(\mathrm{t}, 3 \mathrm{H})$.

\subsubsection{Preparation of poly $\left[\mathrm{C}_{16} \mathrm{VIm}^{+}\right]\left[\mathrm{Br}^{-}\right]$}

Poly $\left[\mathrm{C}_{16} \mathrm{VIm}^{+}\right]\left[\mathrm{Br}^{-}\right]$was prepared by using a common radical polymerization. As presented in Figure 1, $\left[\mathrm{C}_{16} \mathrm{VIm}^{+}\right]\left[\mathrm{Br}^{-}\right](25 \mathrm{mmol}, 5 \mathrm{~g})$, AIBN (0.25 mmol, $0.0412 \mathrm{~g}$ ) were dissolved in $30 \mathrm{~mL}$ dried ethanol in a dry $250 \mathrm{~mL}$ round-bottomed flask. The obtained mixtures were sealed and completely degassed. The flask was then placed in a pre-heated oil bath at $65^{\circ} \mathrm{C}$ for $24 \mathrm{~h}$. After polymerization, the mixture was precipitated into acetone, and then re-dissolved in ethanol. The dissolution-precipitation purification was repeated for several times. The products were dried under vacuum at $40^{\circ} \mathrm{C}$ for $24 \mathrm{~h}$. The obtained poly $\left[\mathrm{C}_{16} \mathrm{VIm}^{+}\right]\left[\mathrm{Br}^{-}\right]$was yellow power $(76 \%$ yield). The molecular weight $\left(M_{\mathrm{n}}\right)$ and polydispersity index (PDI) of poly $\left[\mathrm{C}_{16} \mathrm{VIm}^{+}\right]\left[\mathrm{Br}^{-}\right]$were $10841 \mathrm{~g} / \mathrm{mol}$ and 1.58 respectively as determined by gel permeation chromatography. ${ }^{1} \mathrm{H}-\mathrm{NMR}\left[\mathrm{CDCl}_{3}-\mathrm{d}_{6}, \delta\right.$ ppm relative to TMS]: a $9.50(\mathrm{~s}, 1 \mathrm{H})$, b $8.25(\mathrm{~s}, 1 \mathrm{H}), \mathrm{c} 7.95$ (s, 1H), f $2.85(\mathrm{~m}, 1 \mathrm{H}), \mathrm{d} 5.95(\mathrm{dd}, 1 \mathrm{H})$, e $2.75(\mathrm{dd}$, 1H), g $1.75(\mathrm{t}, 1 \mathrm{H})$, h $1.25(\mathrm{~m}, 2 \mathrm{H})$, i $0.85(\mathrm{~m}, 2 \mathrm{H})$.

\subsubsection{Anion exchange reactions}

Anion exchange reactions (Figure 1) were carried out as described in the literature [24]. A PIL solution was prepared by dissolving poly $\left[\mathrm{C}_{16} \mathrm{VIm}^{+}\right]\left[\mathrm{Br}^{-}\right]$ $(0.1 \mathrm{mmol}, 1.08 \mathrm{~g})$ in $20 \mathrm{~mL}$ ethanol. Meanwhile, $\mathrm{NaBF}_{4}(4 \mathrm{mmol}, 0.44 \mathrm{~g}$ ) was dissolved in $100 \mathrm{~mL}$ of de-ionized water. The aqueous solution of $\mathrm{NaBF}_{4}$ was then added into the obtained ethanol solution of poly $\left[\mathrm{C}_{16} \mathrm{VIm}^{+}\right]\left[\mathrm{Br}^{-}\right]$. Upon mixing, a white precipitant formed immediately. The reaction mixture was stirred at $25^{\circ} \mathrm{C}$ for $24 \mathrm{~h}$, followed by re-precipitating and washing in de-ionized water for at least 3 times.

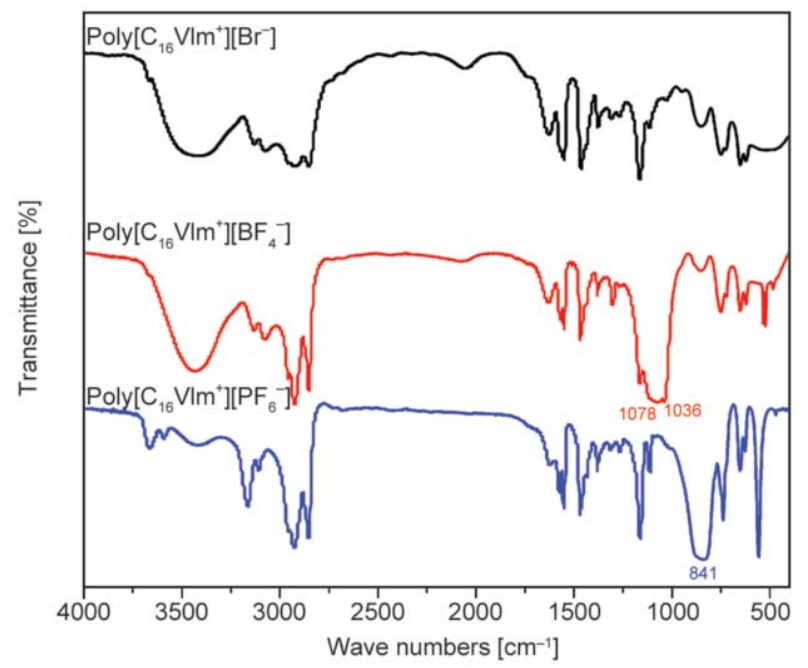

Figure 2. IR spectra of poly $\left[\mathrm{C}_{16} \mathrm{VIm}^{+}\right]\left[\mathrm{X}^{-}\right]\left(\mathrm{X}^{-}=\mathrm{Br}^{-}, \mathrm{BF}_{4}^{-}\right.$, and $\mathrm{PF}_{6}^{-}$).

The resulting product was dried under vacuum at $40^{\circ} \mathrm{C}$ for $24 \mathrm{~h}$. The yield of such an anion exchange reaction was about $80 \%$. A similar procedure was performed with $\mathrm{KPF}_{6}$ to produce poly $\left[\mathrm{C}_{16} \mathrm{VIm}^{+}\right]\left[\mathrm{PF}_{6}{ }^{-}\right]$. In particular, there was no change in chemical composition except anion before and after anion exchange reaction, and accordingly only IR characterization was conducted on these PIL samples. IR spectra (Figure 2) of the poly $\left[\mathrm{C}_{16} \mathrm{VIm}^{+}\right]\left[\mathrm{Br}^{-}\right]$, poly $\left[\mathrm{C}_{16} \mathrm{VIm}^{+}\right]\left[\mathrm{BF}_{4}^{-}\right]$ and poly $\left[\mathrm{C}_{16} \mathrm{VIm}^{+}\right]\left[\mathrm{PF}_{6}{ }^{-}\right]$show a characteristic peak at $1655 \mathrm{~cm}^{-1}$, which is assigned to a stretching vibration of imidazolium ring. In addition, the appearance of the abroad absorption bands at 1036, $1078 \mathrm{~cm}^{-1}$ corresponding to the $\mathrm{BF}_{4}^{-}$and the band at $841 \mathrm{~cm}^{-1}$ corresponding to $\mathrm{PF}_{6}^{-}[25,26]$ is indicative of a successful anion exchange reaction. The anion exchange degree is determined by energy-dispersive $\mathrm{X}$-ray (EDX) spectra, which reveals that there is almost no $\mathrm{Br}^{-}$remained in both poly $\left[\mathrm{C}_{16} \mathrm{VIm}^{+}\right]\left[\mathrm{BF}_{4}^{-}\right]$ and poly $\left[\mathrm{C}_{16} \mathrm{VIm}^{+}\right]\left[\mathrm{PF}_{6}{ }^{-}\right]$.

\subsection{Characterization \\ ${ }^{1} H N M R$}

${ }^{1} \mathrm{H}$ nuclear magnetic resonance $\left({ }^{1} \mathrm{H}\right.$ NMR $)$ spectra with $\mathrm{CDCl}_{3}$ or DMSO- $\mathrm{d}_{6}$ as solvents were performed on a FTNMR Digital Avance AV 400 MHz (Bruker, Germany) at $298.15 \mathrm{~K}$. 
$G P C$

The molecular weight was determined by gel permeation chromatography (GPC) comprised of a Waters SEC equipped with two $300 \mathrm{~mm}$ Waters Styrgel solvent-saving columns (molecular weight ranges: $\left.1 \cdot 10^{2}-5 \cdot 10^{3}, 5 \cdot 10^{3}-6 \cdot 10^{5}\right)$ and a Waters 2414 refractive index detector (Waters, America). It should be pointed out that the presence of charged groups in PILs would result in electrostatic repulsions and accordingly polymer chain aggregation in GPC measurement, which could be screened by the addition of a small amount of $\operatorname{LiTf}_{2} \mathrm{~N}$ as proposed by Nulwala [27]. Therefore, we changed the $\mathrm{Br}^{-}$as $\mathrm{LiTf}_{2}{ }^{-}$and then conducted the GPC measurement using tetrahydrofuran (THF) containing $10 \mathrm{mM} \mathrm{LiTf}_{2} \mathrm{~N}$ as eluent at a flow rate of $0.8 \mathrm{~mL} / \mathrm{min}$ at $30^{\circ} \mathrm{C}$.

\section{$I R$}

Infrared spectra were collected at room temperature using a Nicolet Avatar 370 spectrometer (Nicolet, America) in the range of $4000-400 \mathrm{~cm}^{-1}$.

\section{POM}

Liquid crystalline textures were characterized by polarized optical microscopy (POM) (Leica DM 2500P, Leica Microsystems, Germany). A magnification of $50 \times$ was used and photomicrographs of various phases were taken by employing a digital camera. In an effort to avoid organic solvent evaporation, the sample was shifted to a microscope slide and covered by a cover glass as soon as possible [28].

\section{$X R D$}

Wide-angle X-ray diffraction (XRD) patterns of PIL solid powder were recorded using a Rigaku D/MAX2550PC (Rigaku, Japan) with $\mathrm{CuK}$ radiation $(\lambda=$ $1.5406 \AA$ ). The irradiation ranged from 3 to $50^{\circ}$, a step of $0.02^{\circ}$ and $0.6 \mathrm{~s}$ per step with a symmetric reflection geometry. The angle of diffraction was varied from 3 to $50^{\circ}$ to identify changes in the crystal structure. In order to explore the exact mesophase structure of PILs, small-angle XRD were employed for characterization. Small-angle XRD patterns were recorded on a Rigaku D/MAX-2250 V diffractometer $(40 \mathrm{kV}$ and $40 \mathrm{~mA})$ in the range of $0.5-10^{\circ}$.

\section{SAXS}

The structural evolution of PILs during in-situ solvent evaporation was detected by synchrotron small angle X-ray scattering (SAXS). The SAXS measure- ments were performed at the BL16B1 beamline of the Shanghai Synchrotron Radiation Facility (SSRF) in China. The wavelength was $1.24 \AA$ and the sample-to-detector distance was set at $357 \mathrm{~mm}$. The twodimensional SAXS patterns were converted into onedimensional SAXS profiles using Fit2D software.

For PIL solid powder, SAXS measurements were conducted using a Xeuss SAXS system (Xenocs SA, France) with $\mathrm{Cu} K \alpha$ radiation (wavelength $\lambda=$ $0.154 \mathrm{~nm}$ ). The sample-to-detector distance is $1404.6 \mathrm{~mm}$. The two-dimensional (2D) SAXS patterns were recorded in every $1800 \mathrm{~s}$ by a Mar 345 image plate as a detector. Fit 2D software package was used to analyze the 2D SAXS patterns. The 2D SAXS patterns were background corrected and then averaged over all directions at constant scattering vector $q(q=(4 \pi \sin \theta) / \lambda$, where $2 \theta$ is the scattering angle), resulting in one dimensional scattering intensity curves ( $I$ vs. $q$ ).

DSC

Differential scanning calorimetry (DSC) was performed on TA Q2000 (TA Instruments, America). The samples were first heated up to $150^{\circ} \mathrm{C}$, and then were subjected to a cooling process from 150 to $-50^{\circ} \mathrm{C}$ at the cooling rate of $10 \mathrm{~K} / \mathrm{min}$. They were kept at $-50^{\circ} \mathrm{C}$ for $2 \mathrm{~min}$. Finally, the samples were reheated to $150^{\circ} \mathrm{C}$ at the heating rate of $10 \mathrm{~K} / \mathrm{min}$.

\section{Results and discussion}

Polymerization of IL possessing vinyl groups provides a good approach for improving the mechanical durability of PIL-based functional materials with ordered structures. Generally, long alkyl chain is in favor of the ordered packing of PILs [22]. In this work, therefore, our emphases are on the inner structures of the poly $\left[\mathrm{C}_{16} \mathrm{VIm}^{+}\right]\left[\mathrm{X}^{-}\right]$.

\subsection{Structural evolution of poly $\left[\mathrm{C}_{16} \mathrm{VIm}^{+}\right]\left[\mathrm{X}^{-}\right]$ during in-situ solvent evaporation}

\subsubsection{Poly $\left[\mathrm{C}_{16} \mathrm{VIm}^{+}\right]\left[\mathrm{Br}^{-}\right]$}

In order to detect its structural evolution during insitu solvent evaporation, the poly $\left[\mathrm{C}_{16} \mathrm{VIm}^{+}\right]\left[\mathrm{Br}^{-}\right]$ was first dissolved in n-propanol (n-PrOH), forming a homogeneous and very viscous solution. Upon evaporation, the n-PrOH content in the binary system of PIL/solvent would decrease. The binary mixture with an initial $n-\mathrm{PrOH}$ content of $52.1 \%(\mathrm{w} / \mathrm{w})$ (the ratio of solvent to PIL) was prepared, and then was subject to synchrotron SAXS analysis. Specifically, 
the synchrotron SAXS data were recorded at intervals of about 2 minutes in an attempt to achieve insitu detection.

SAXS results for the binary mixtures of poly $\left[\mathrm{C}_{16} \mathrm{VIm}^{+}\right]\left[\mathrm{Br}^{-}\right]$with n-PrOH (the n-PrOH content varying within the range of 52.1 to $23.2 \%(\mathrm{w} / \mathrm{w})$ ) are presented in Figure 3. At the n-PrOH content of $52.1 \%(\mathrm{w} / \mathrm{w})$, the average 1D data exhibit a broad diffraction peak positioned at $q=0.215 \AA^{-1}$ (Figure 3a), indicative of a very weakly ordered structure. This is further confirmed by the corresponding 2D SAXS images, in which a broad, isotropic ring is observed at a higher scattering vector (Figure $3 b$ ). When $\mathrm{n}-\mathrm{PrOH}$ content falls to $33.3 \%(\mathrm{w} / \mathrm{w})$, the binary mixture transforms from viscous liquid to a pale-yellow physical gel. The 1D SAXS patterns of the gel display a first-order peak at lower $q\left(q=0.193 \AA^{-1}\right)$, and a weak diffraction peak positioned at $q=$ $0.386 \AA^{-1}$ (Figure 3a). The position for these two peaks follows the ratio of $1: 2$, suggesting an ordered lamellar structure with a repeat distance of $32.5 \AA^{-1}$. Notably, at lower n-PrOH content of $23.2 \%(w / w)$,

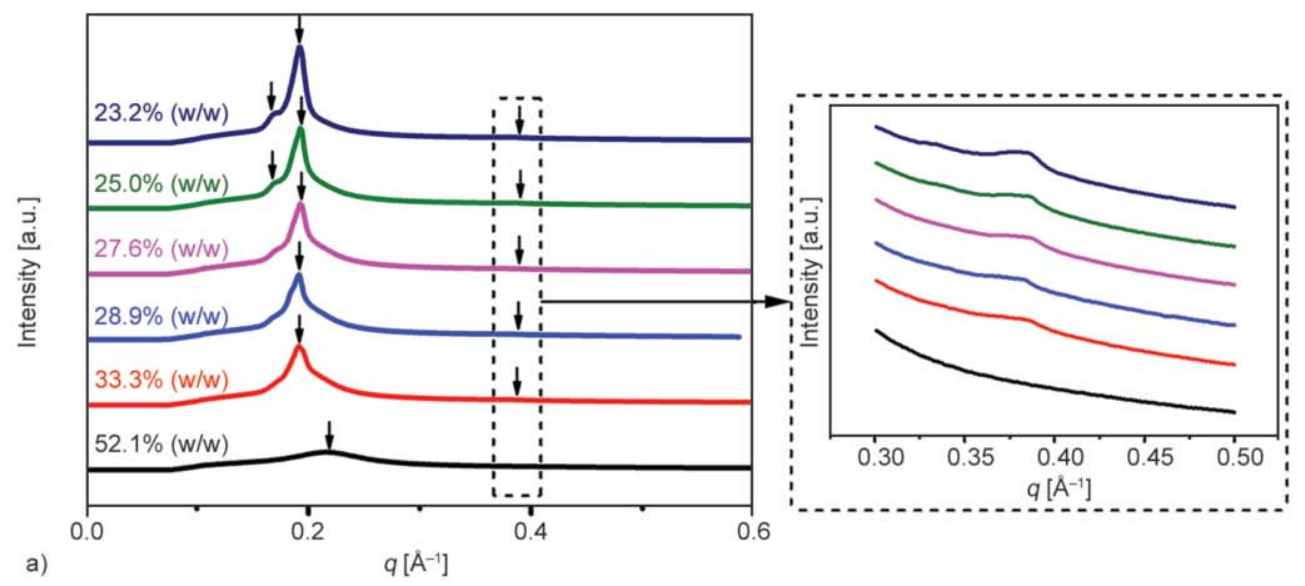

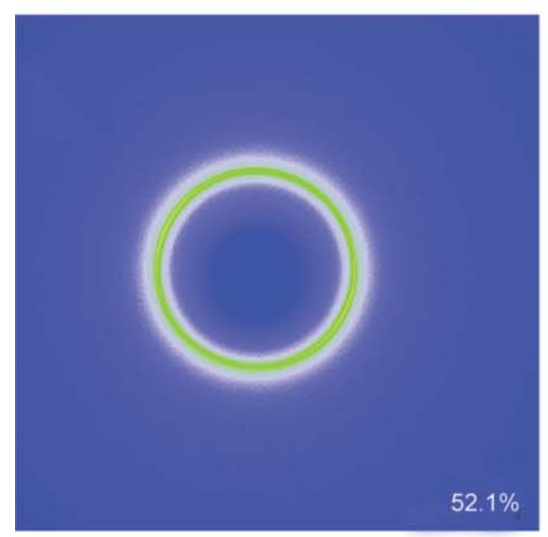

b)

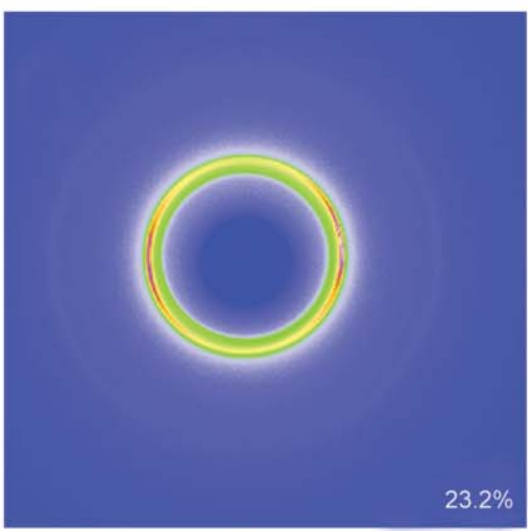

c)

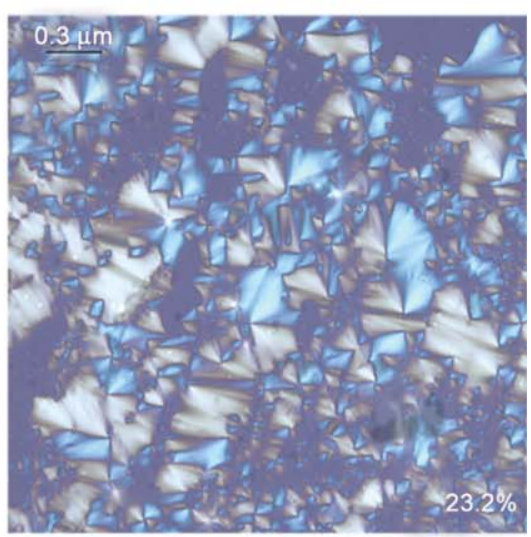

d)

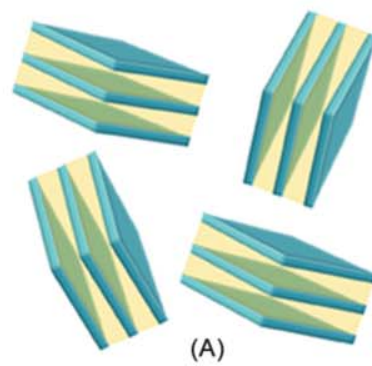

Figure 3. (a) Average SAXS data collected on a binary mixture of poly $\left[\mathrm{C}_{16} \mathrm{VIm}^{+}\right]\left[\mathrm{Br}^{-}\right]$with $23.2-52.1 \%(\mathrm{w} / \mathrm{w}) \mathrm{n}-\mathrm{PrOH}$. $(\mathrm{b}, \mathrm{c})$ 2D SAXS pattern of a binary mixture of poly $\left[\mathrm{C}_{16} \mathrm{VIm}^{+}\right]\left[\mathrm{Br}^{-}\right]$with 52.1 and $23.2 \%$ (w/w) n-PrOH. (d) Representative polarized optical micrograph $(\mathrm{POM})$ of a binary mixture of poly $\left[\mathrm{C}_{16} \mathrm{VIm}^{+}\right]\left[\mathrm{Br}^{-}\right]$with $23.2 \%(\mathrm{w} / \mathrm{w}) \mathrm{n}-$ PrOH. (e) Schematic illustration of the structural evolution from (A) weakly ordered lamellar, (B) perforated lamellar to $(\mathrm{C})$ the less ordered packing of these perforations upon solvent evaporation. 
the averaged 1D data show two diffraction peaks at $q=0.192,0.384 \AA^{-1}(1: 2)$ suggestive of a lamellar structure with the $d$-spacing of $32.7 \AA$. Under polarized light, the binary mixture displays focal conic fan textures (Figure 3d), a characteristic of the smectic A phase [29]. It is noteworthy that a weak shoulder at $q=0.168 \AA^{-1}$ is also observed in 1D SAXS patterns. This shoulder positioned at $\sqrt{3} / 2 q$ (below the first-order Bragg reflection) has been indexed to the emergence of a perforated lamellar structure $[21,30$, 31]. The corresponding 2D SAXS pattern shows a Bragg ring at high $q$ with the scattered X-ray intensity predominantly directed in the equatorial direction (Figure 3c). The reduction in the breadth of the first-order diffraction peak and the emergence of a shoulder positioned at $\sqrt{3} / 2 q$ demonstrate the structural evolution from very weakly ordered to perforated lamellar structure with solvent evaporation as described in Figure 3e (A, B). This means that the change in solvent content can readily alter the structure of the lyotropic mesophase.

\subsubsection{Poly $\left[\mathrm{C}_{16} \mathrm{VIm}^{+}\right]\left[\mathrm{BF}_{4}{ }^{-}\right]$}

The averaged SAXS data collected on the binary mixture with a DMF content varying between 18.1 and $35.0 \%(\mathrm{w} / \mathrm{w})$ are given in Figure $4 \mathrm{a}$, in which three similar curves are observed within the experimental range of DMF content, suggesting a similar structural characteristic. At the DMF content of $18.1 \%(\mathrm{w} / \mathrm{w})$, the binary mixture is found to be a physical gel with liquid crystalline mesophases (Figure 4c). 2D SAXS images collected on this sample show an isotropic ring with a slight higher scattered X-ray intensity in the equatorial direction (Figure $4 \mathrm{~b}$ ). The corresponding integrated 1D scattering data show three diffraction peaks positioned at a ratio of 1:2:4, which means a well-defined lamellar structure. Furthermore, as shown in Figure 4a inset, another set of weak diffraction peaks occur at a ratio of $\sqrt{6}, \sqrt{12}$ and $\sqrt{16}$. This set of reflections index to, most likely, a bicontinous cubic phase with Ia3d symmetry $[32,33]$. Obviously, this physical gel with $18.1 \%$ (w/w) DMF exhibits ordered lamellar structures with a tiny minority of bicontinuous cubic phase (Figure 4d). The co-existence of lamellar structure with cubic phase (eg. Ia3d or Pn $3 \mathrm{~m}$ ) has also been observed in the self-assembly of cationic surfactant/ethoxylated polyions complex salts by the addition of n-decanol [34] and imidazolium-based zwitterions with lithium bis(trifluoromethanesulfonyl)imide [35].

\subsubsection{Poly $\left[\mathrm{C}_{16} \mathrm{VIm}^{+}\right]\left[\mathrm{PF}_{6}^{-}\right]$}

In order to understand the effect of types of anion on PIL microstructures, another polyatomic inorganics, $\mathrm{PF}_{6}{ }^{-}$, was selected as the counter-anion. As shown in Figure 5a, one broad diffraction peak appears at $q=$ $0.196 \AA^{-1}$, and there are no other reflections observed in 1D SAXS patterns for the binary mixtures of poly $\left[\mathrm{C}_{16} \mathrm{VIm}^{+}\right]\left[\mathrm{PF}_{6}{ }^{-}\right]$with DMF content of 26.5 and $34.9 \%(\mathrm{w} / \mathrm{w})$. In addition, a very weak diffraction peak occurs at the position of $2 q$ when the DMF content decreases to $17.8 \%(\mathrm{w} / \mathrm{w})$. The corresponding 2D SAXS images (Figure 5b) display a broad and isotropic ring, suggesting the emergence of a weakly ordered morphology without long-range periodicity (Figure 5d). This morphology can be further confirmed by POM, in which a very weak optical birefringence is observed (Figure 5c). Obviously, the poly $\left[\mathrm{C}_{16} \mathrm{VIm}^{+}\right]\left[\mathrm{PF}_{6}^{-}\right]$displays a weaker structural ordering when compared with poly $\left[\mathrm{C}_{16} \mathrm{VIm}^{+}\right]\left[\mathrm{BF}_{4}{ }^{-}\right]$ and poly $\left[\mathrm{C}_{16} \mathrm{VIm}^{+}\right]\left[\mathrm{Br}^{-}\right]$. This behavior is likely due to the fact that $\mathrm{PF}_{6}{ }^{-}$exhibits stronger interaction with imidazolium cations than $\mathrm{BF}_{4}^{-}$and $\mathrm{Br}^{-}$[36], which reduces the chain mobility, and hence hinders the ordering packing of PIL molecules.

\subsection{Microstructures in dried} poly $\left[\mathrm{C}_{16} \mathrm{VIm}^{+}\right]\left[\mathrm{X}^{-}\right]$

For the fabrication of PIL-based soft template, it is of vital importance for understanding what kind of structure presented in PIL solid bulk. The structural evolution of poly $\left[\mathrm{C}_{16} \mathrm{VIm}^{+}\right]\left[\mathrm{X}^{-}\right]$during in-situ solvent evaporation was investigated in detail in Section 3.1. In an effort to further explore the microstructure in solid bulk, the poly $\left[\mathrm{C}_{16} \mathrm{VIm}^{+}\right]\left[\mathrm{X}^{-}\right]$samples were thoroughly dried in vacuum at $80^{\circ} \mathrm{C}$ for at least 24 hours. These PIL powders are found to be in almost completely drying state as evidenced by TGA measurement (the TGA results are not presented here), in which only a less amount of solvent $(<5 \mathrm{wt} \%)$ remains in these samples.

\subsubsection{DSC}

The ordered packing of side chains of a polymer can be detected by DSC. As shown in Figure 6, one peak appears in DSC curves for each of PIL samples, implying that these PILs are in a crystalline state with respect to the side chains. Notably, the alkyl side chains in poly $\left[\mathrm{C}_{16} \mathrm{VIm}^{+}\right]\left[\mathrm{Br}^{-}\right]$, poly $\left[\mathrm{C}_{16} \mathrm{VIm}^{+}\right]\left[\mathrm{PF}_{6}{ }^{-}\right]$ and poly $\left[\mathrm{C}_{16} \mathrm{VIm}^{+}\right]\left[\mathrm{BF}_{4}^{-}\right]$crystallize at 24,35 , and $42^{\circ} \mathrm{C}$, respectively. Similar results were reported in 


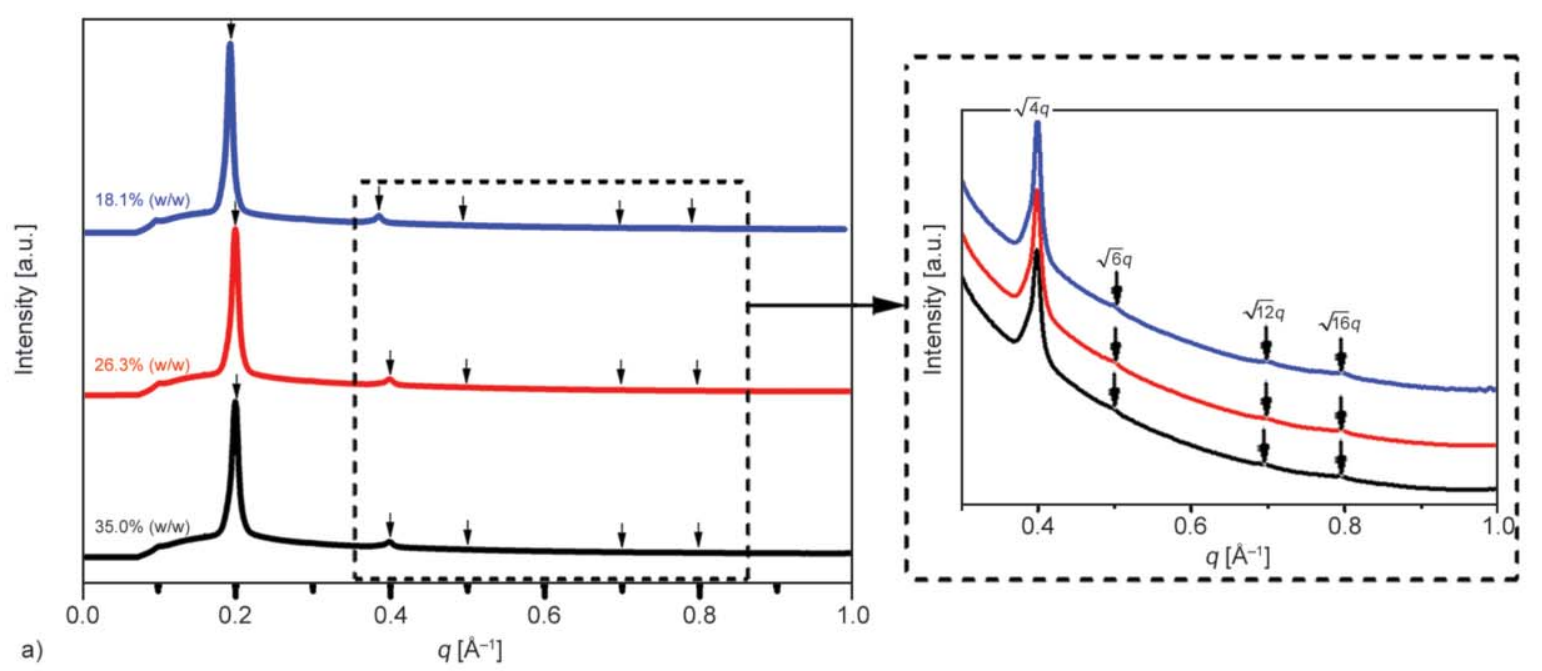

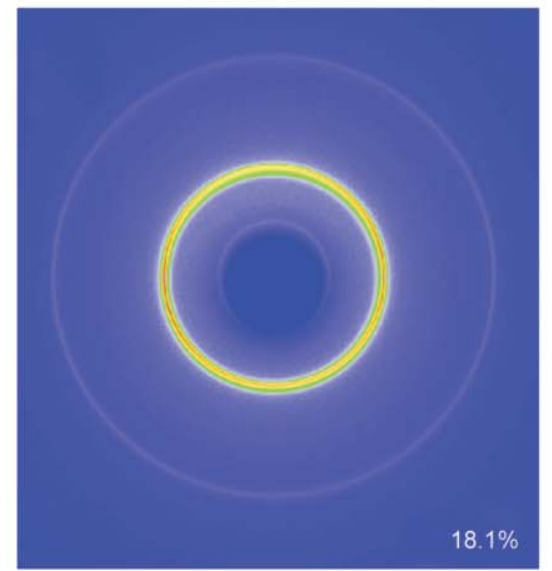

b)
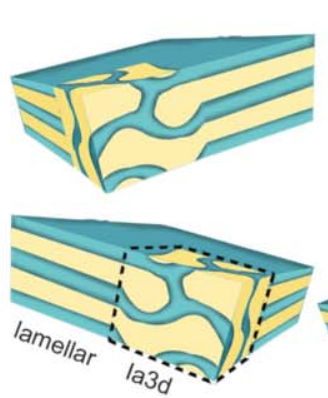

(A)

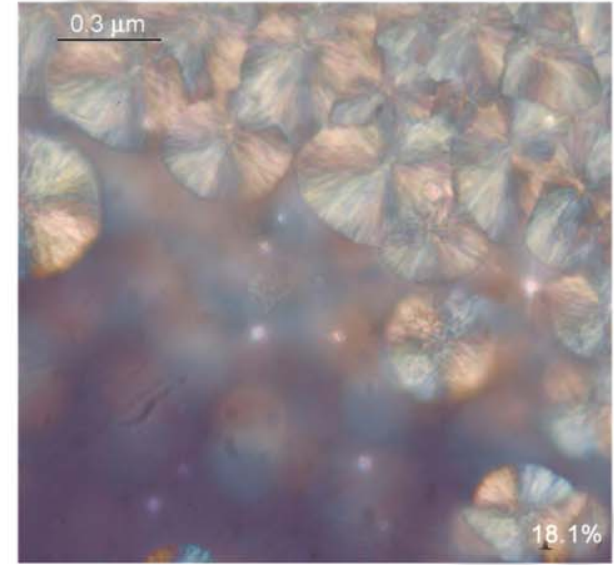

c)

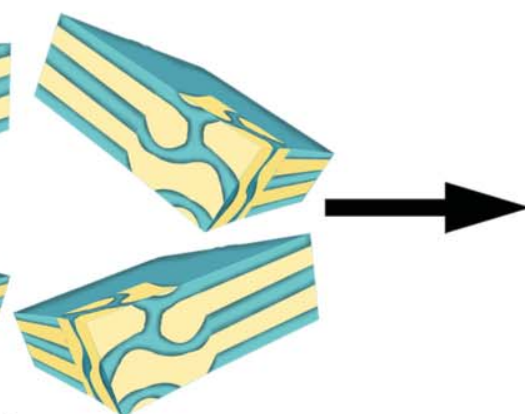

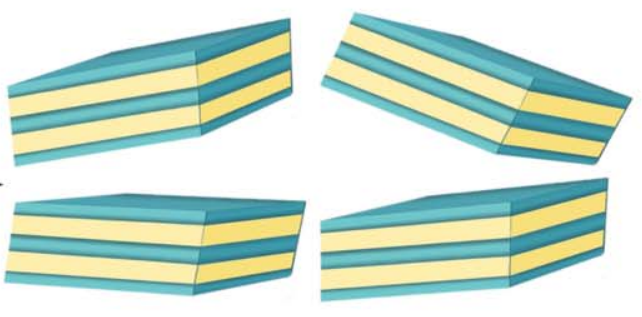

(B)

d)

Figure 4. (a) Average SAXS data collected on a binary mixture of poly $\left[\mathrm{C}_{16} \mathrm{VIm}^{+}\right]\left[\mathrm{BF}_{4}^{-}\right]$with $18.1,26.3$ and $35.0 \%$ (w/w) DMF. (b, c) 2D SAXS pattern and of POM collected on a binary mixture of poly $\left[\mathrm{C}_{16} \mathrm{VIm}^{+}\right]\left[\mathrm{BF}_{4}^{-}\right]$with 18.1\% (w/w) DMF. (d) Schematic illustration of the transformation from (A) a lamellar structure with a tiny minority of bicontinuous cubic phase (Ia3d) to (B) an ordered packing of lamellar structure upon solvent evaporation.

previous work [37], where the crystallization temperatures were within $21-35^{\circ} \mathrm{C}$ when the lengths of alkyl side chains of poly $\left[\mathrm{C}_{16} \mathrm{VIm}^{+}\right]\left[\mathrm{Br}^{-}\right]$varied in the range of 16-18.

\subsubsection{X-ray diffraction}

Wide-angle $\mathrm{X}$-ray diffraction patterns of the dried poly $\left[\mathrm{C}_{16} \mathrm{VIm}^{+}\right]\left[\mathrm{X}^{-}\right]\left(\mathrm{X}^{-}=\mathrm{Br}^{-}, \mathrm{PF}_{6}^{-}, \mathrm{BF}_{4}^{-}\right)$are shown in Figure 7a. With $\mathrm{Br}^{-}$and $\mathrm{BF}_{4}{ }^{-}$as counteranion, the PILs exhibit typical peaks at $2 \theta$ of $21-24^{\circ}$ [38], a profile characteristic of the crystalline phase. By contrast, a less sharp diffractions is found for poly $\left[\mathrm{C}_{16} \mathrm{VIm}^{+}\right]\left[\mathrm{PF}_{6}{ }^{-}\right]$at the same $2 \theta$ position, indicating a less perfect crystalline structure. It should be pointed out that the diffraction peaks appears at $2 \theta$ between 5.2 and $5.7^{\circ}$ for these PIL samples, which 

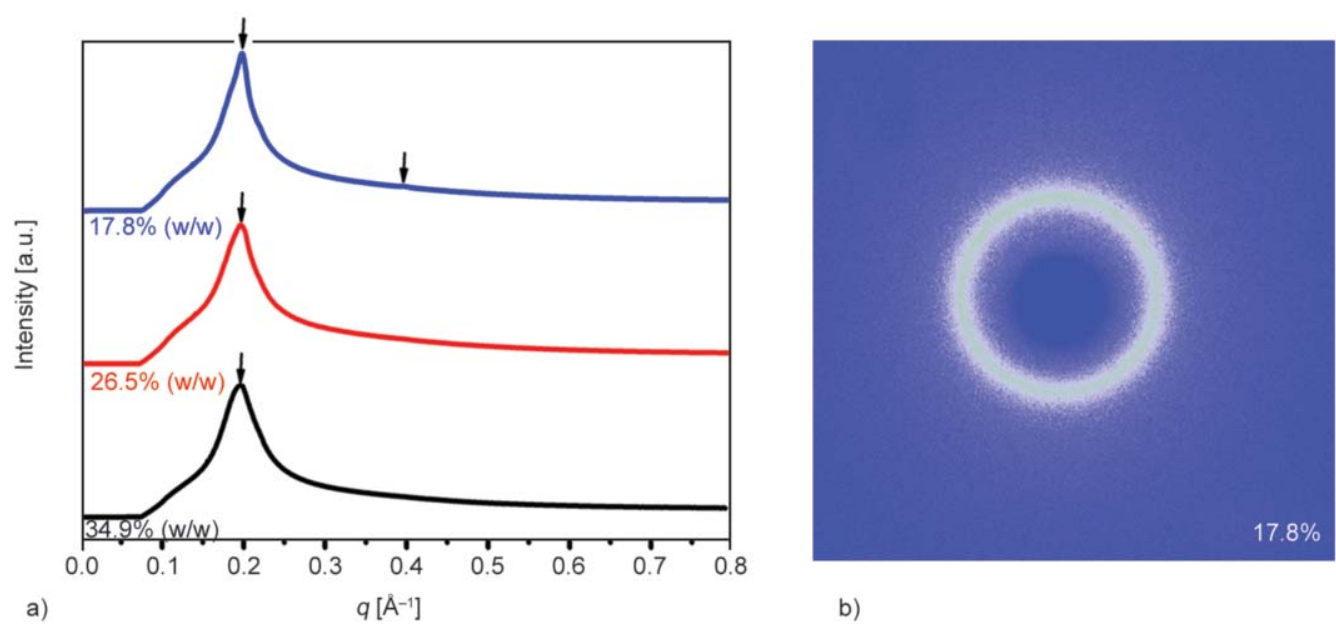

b)
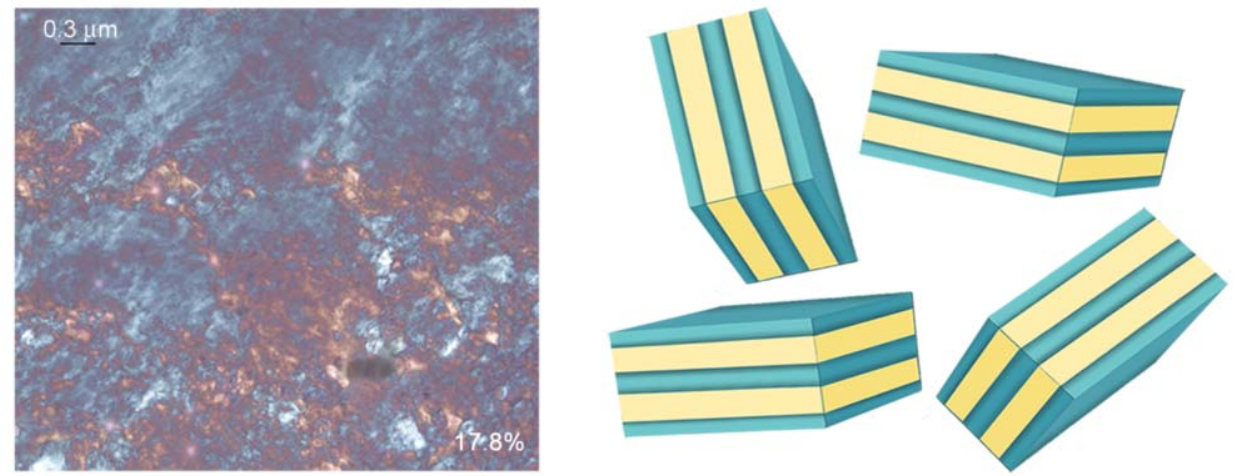

c)

d)

Figure 5. (a) Average SAXS data collected on a binary mixture of poly $\left[\mathrm{C}_{16} \mathrm{VIm}^{+}\right]\left[\mathrm{PF}_{6}{ }^{-}\right]$with $17.8,26.5$, and $34.9 \%$ (w/w) DMF. (b, c) 2D SAXS pattern and POM collected on a binary mixture of poly $\left[\mathrm{C}_{16} \mathrm{VIm}^{+}\right]\left[\mathrm{PF}_{6}^{-}\right]$with $17.8 \%(\mathrm{w} / \mathrm{w})$ DMF. (d) Schematic illustration of a weakly ordered lamellar morphology.

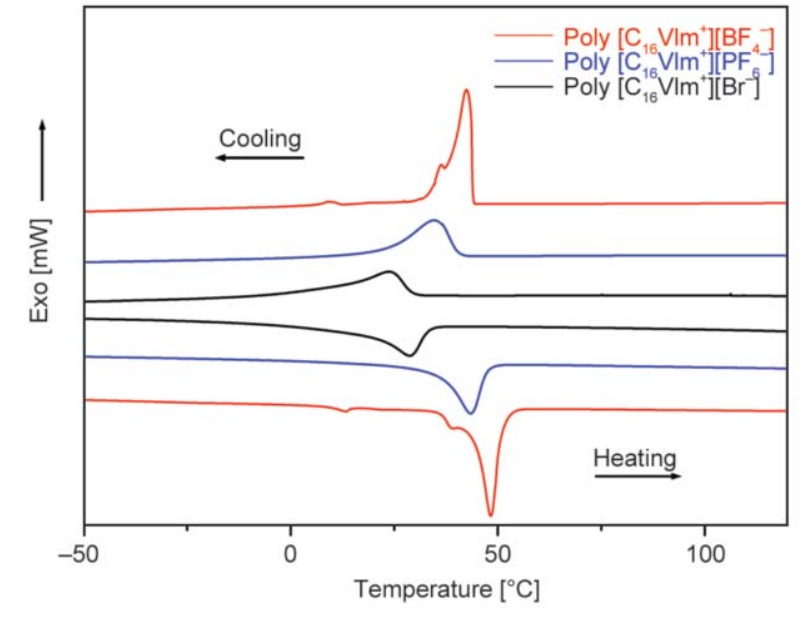

Figure 6. DSC curves of the dried poly $\left[\mathrm{C}_{16} \mathrm{VIm}^{+}\right]\left[\mathrm{X}^{-}\right]\left(\mathrm{X}^{-}=\right.$ $\mathrm{Br}^{-}, \mathrm{PF}_{6}^{-}$, and $\left.\mathrm{BF}_{4}^{-}\right)$

provides preliminary hints of an ordered orientation at the scale of alkyl side chains. In order to put more insight into this ordered inner structures, small-angle $\mathrm{X}$-ray diffraction measurements were performed at room temperature. As depicted in Figure 7b, in the small angle region, there are two reflections at the equidistant positions in the $\mathrm{d}$ scale as 1:2 (the firstorder diffraction) for these three samples, which seems to be a lamellar mesomorphous structure. Furthermore, the poly $\left[\mathrm{C}_{16} \mathrm{VIm}^{+}\right]\left[\mathrm{BF}_{4}^{-}\right]$displays two additional peaks at $2 \theta=3.18$ and $6.41^{\circ}$, corresponding to a reciprocal $d$-spacing of 1:2.

\subsubsection{SAXS}

Complementary information about the exact structures of PILs was obtained by SAXS. As shown in Figure $7 \mathrm{c}$, the dried poly $\left[\mathrm{C}_{16} \mathrm{VIm}^{+}\right]\left[\mathrm{Br}^{-}\right]$exhibits typical lamellar structure demonstrated by the appearance of two peaks positioned at a ratio of 1:2. Furthermore, two peaks on either side of the firstorder reflection $\left(q=0.198 \AA^{-1}\right)$ appear at 0.92 and $1.13 \AA^{-1}$. These Bragg peaks at $0.95 q, q, 1.14 q$ are assigned to the (101), (003) and (102) reflections of a hexagonal perforated lamellar (HPL) structure that features the packing of the in-plane perforations [31]. The formation of a HPL phase normally involves in the occurrence of random perforations within the lamellar sheets, and then in-plane hexagonal close- 


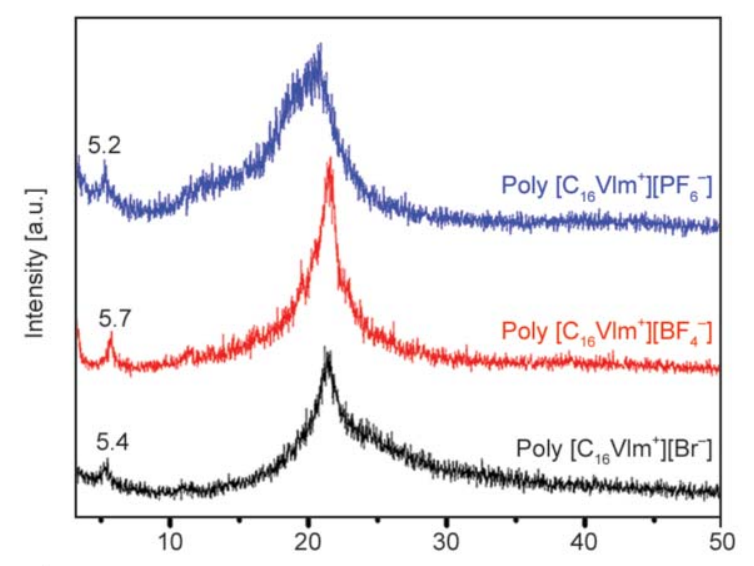

a)

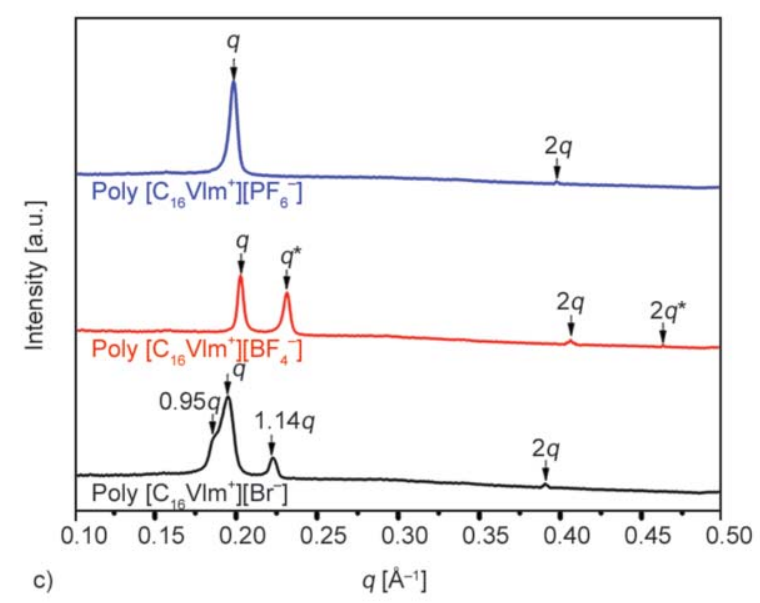

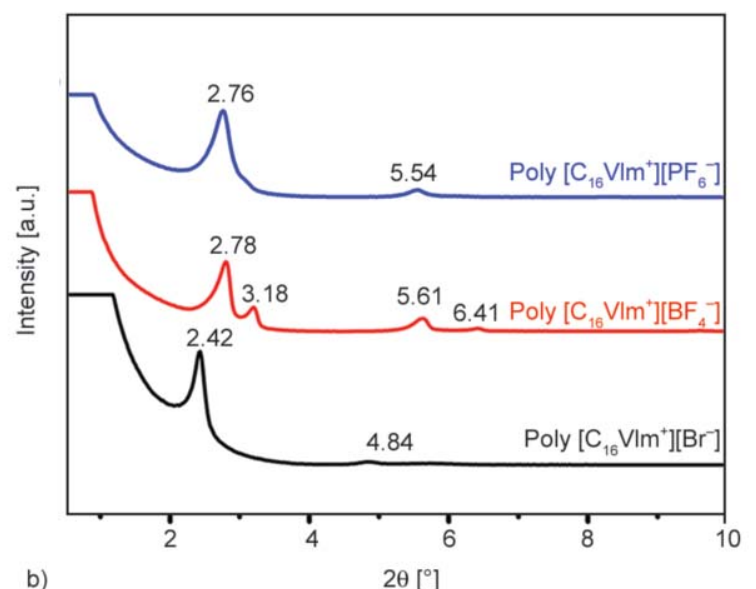

b)

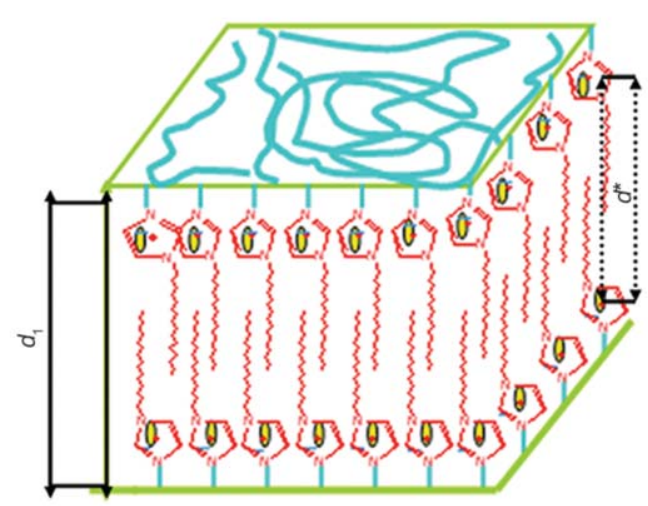

d)

Figure 7. (a) Wide-angle X-ray diffraction, (b) small-angle X-ray diffraction and (c) average SAXS data of the dried poly $\left[\mathrm{C}_{16} \mathrm{VIm}^{+}\right]\left[\mathrm{X}^{-}\right]\left(\mathrm{X}^{-}=\mathrm{Br}^{-}, \mathrm{BF}_{4}^{-}\right.$, and $\left.\mathrm{PF}_{6}^{-}\right)$. (d) Schematic illustration of an interdigitated packing of alkyl tails in the lamellar sheets.

packing of these perforations [23]. Here the absence of peak at $\sqrt{3} q$, therefore, indicates a slightly less ordered array of the pore structures within the lamellar sheets (Figure 3e (C)).

For poly $\left[\mathrm{C}_{16} \mathrm{VIm}^{+}\right]\left[\mathrm{BF}_{4}{ }^{-}\right]$, two set of reflections at $q, 2 q$, and $q^{*}, 2 q^{*}$ are observed in the 1D SAXS data (Figure 7c), which is in good agreement with that shown in Figure $7 \mathrm{~b}$. The ratio of 1:2 (positioned at $q$, $2 q$ ) confirms the presence of lamellar structure, while the $d$-spacing determined from the other set of reflections at $q^{*}, 2 q^{*}$ might be resulted from the intermolecular imidazolium-to-imidazolium packing (namely $d^{*}$ in Figure 7d) [39]. It should be pointed out that the tiny minority of bicontinuous cubic phase in the lamellar sheets presented in the poly $\left[\mathrm{C}_{16} \mathrm{VIm}^{+}\right]\left[\mathrm{BF}_{4}{ }^{-}\right]$ solution or gel disappears in its solid bulk (Figure 4d). Generally, molecular self-assembly structures are closely related to the space-filling requirement of the alkyl chains. With solvent evaporation, the space required for the ordered arrangement of long alkyl chains decreases. In this case, the bicontinuous cubic phase has to convert into lamellar structure in order to minimize the conformational energy. In fact, such a space-filling dependence can also be verified by the fact that the decrease of temperature facilitates the transition from a bicontinuous cubic phase to a lamellar phase [34, 35].

In the case of poly $\left[\mathrm{C}_{16} \mathrm{VIm}^{+}\right]\left[\mathrm{PF}_{6}{ }^{-}\right]$, the average $1 \mathrm{D}$ SAXS profiles (Figure 7c) show two diffractions peaks at the positions with a ratio of $1: 2$, which is analogous to those in Figure 5a. Specifically, the dried poly $\left[\mathrm{C}_{16} \mathrm{VIm}^{+}\right]\left[\mathrm{PF}_{6}{ }^{-}\right]$displays a sharper first-order diffraction than the corresponding gel sample, implying that the former possesses more ordered lamellar structures.

It should be pointed out that the dried PIL samples as a whole display a lamellar morphology regardless of in-plane perforations. In a lamellar structure, the packing model can be deduced by the relationship between the length of alkyl chain and $d$-spacing. Since the increase of one carbon atom in a stretched alkyl chain is about $1.25 \AA$, the full length of $\mathrm{C}_{16}$ tail 
is estimated about $20.0 \AA$, which is larger than half of the $d$-spacings for these dried PIL samples (the $d$ spacings $\left(d_{1}\right)$ for the dried poly $\left[\mathrm{C}_{16} \mathrm{VIm}^{+}\right]\left[\mathrm{X}^{-}\right]\left(\mathrm{X}^{-}=\right.$ $\mathrm{Br}^{-}, \mathrm{BF}_{4}^{-}$, and $\left.\mathrm{PF}_{6}^{-}\right)$vary in the range of $30.8-$ $32.0 \AA$ ). This means an interdigitated packing of alkyl tails (Figure 7d), resembling with that observed in PIL-based liquid crystalline [40, 41], exists in PIL solid bulk.

\section{Conclusions}

$\mathrm{N}$-alkyl imidazolium-based PILs with different counteranions were successfully synthesized by a common free radical solution polymerization. The prepared PILs were dissolved in organic solvent to form a homogenous solution, which was utilized to explore the structural evolution of PIL assemblies during in-situ solvent evaporation. It was shown that a weakly ordered lamellar structure was formed in a binary mixture of poly $\left[\mathrm{C}_{16} \mathrm{VIm}^{+}\right]\left[\mathrm{Br}^{-}\right]$with $52.1 \%(\mathrm{w} / \mathrm{w}) \mathrm{n}-\mathrm{PrOH}$. With solvent evaporation, the n-PrOH content dropped to $33.3 \%(\mathrm{w} / \mathrm{w})$, and the binary mixture became a pale-yellow physical gel adopting perforated lamella morphology. Upon complete evaporation, an in-plane hexagonal packing of these perforations with a less ordering dominated PIL solid bulk. Unlike poly $\left[\mathrm{C}_{16} \mathrm{VIm}^{+}\right]\left[\mathrm{Br}^{-}\right]$, the poly $\left[\mathrm{C}_{16} \mathrm{VIm}^{+}\right]\left[\mathrm{BF}_{4}^{-}\right]$exhibited ordered lamellar structures with a tiny minority of bicontinuous cubic phase over a wide range of DMF content. The bicontinuous cubic phase, however, disappeared when DMF evaporated almost completely. The transformation from the co-existence of lamellar structure with cubic phase to lamellar morphology was due to the minimization of the conformational energy caused by the decrease in space-filling required for alkyl chain arrangement. In the case of poly $\left[\mathrm{C}_{16} \mathrm{VIm}^{+}\right]\left[\mathrm{PF}_{6}^{-}\right]$, a lamellar morphology was maintained during solvent evaporation, but the degree of ordering was slightly enhanced when the PIL samples were in a dried state. Furthermore, an interdigitated packing of alkyl tails dominated the lamellar sheets of the dried poly $\left[\mathrm{C}_{16} \mathrm{VIm}^{+}\right]\left[\mathrm{X}^{-}\right]\left(\mathrm{X}^{-}=\mathrm{Br}^{-}\right.$, $\mathrm{PF}_{6}^{-}$, and $\left.\mathrm{BF}_{4}^{-}\right)$. This work demonstrates the possibilities of engineering PIL-based functional materials with well-defined ordered structures by simply changing counteranion and solvent content.

\section{Acknowledgements}

This work was supported by Natural Science Foundation of Zhejiang Province (Grant No. LY13B040004 and LY13B030008), and Science and Technology Department of Zhejiang Province Foundation (Grant No. 2014C37073). We thank BL16B1 beamline at Shanghai Synchrotron Radiation Facility (SSRF) for providing the beam time.

\section{References}

[1] Binnemans K.: Ionic liquid crystals. ChemInform, 11, 4148-4204 (2005). https://doi.org/10.1002/chin.200603266

[2] Renna L. A., Boyle C. J., Gehan T. S., Venkataraman D.: Polymer nanoparticle assemblies: A versatile route to functional mesostructures. Macromolecules, 18, 63536368 (2015).

https://doi.org/10.1021/acs.macromol.5b00375

[3] Chen H., Kong J.: Hyperbranched polymers from $\mathrm{A}_{2}+$ $\mathrm{B}_{3}$ strategy: Recent advances in description and control of fine topology. Polymer Chemistry, 7, 3643-3663 (2016).

https://doi.org/10.1039/C6PY00409A

[4] Kong J., Schmalz T., Motz G., Muiller A. H.: Novel hyperbranched ferrocene-containing poly(boro)carbosilanes synthesized via a convenient ' $\mathrm{A}_{2}+\mathrm{B}_{3}$ ' approach. Macromolecules, 44, 1280-1291(2011).

https://doi.org/10.1021/ma1029086

[5] Chen H., Zhang S., Kong J.: Topological analysis and intramolecular cyclic feature evaluation of polymers derived from $A_{m}+B_{n}$ step-growth polymerization. Polymer Chemistry, 6, 909-916 (2015).

https://doi.org/10.1039/C4PY01693A

[6] Bang J., Jeong U., Ryu D. Y., Russell T. P., Hawker C. J.: Block copolymer nanolithography: Translation of molecular level control to nanoscale patterns. Advanced Materials, 21, 4769-4792 (2009).

https://doi.org/10.1002/adma.200803302

[7] Gin D. L., Gu W., Pindzola B. A., Zhou W-J.: Polymerized lyotropic liquid crystal assemblies for materials applications. Accounts of Chemical Research, 34, 973980 (2001).

https://doi.org/10.1021/ar000140d

[8] Xu T., Stevens J., Villa J. A., Goldbach J. T., Guarini K. W., Black C. T., Hawker C. J., Russell T. P.: Block copolymer surface reconstuction: A reversible route to nanoporous films. Advanced Functional Materials, 13, 698-702 (2003).

https://doi.org/10.1002/adfm.200304374

[9] Connal L. A., Lynd N. A., Robb M. J., See K. A., Jang S. G., Spruell J. M., Hawker C. J.: Mesostructured block copolymer nanoparticles: Versatile templates for hybrid inorganic/organic nanostructures. Chemistry of Materials, 24, 4036-4042 (2012).

https://doi.org/10.1021/cm3011524 
[10] Li Z., Ma J., Lee N. S., Wooley K. L.: Dynamic cylindrical assembly of triblock copolymers by a hierarchical process of covalent and supramolecular interactions. Journal of the American Chemical Society, 133, 1228 1231 (2011). https://doi.org/10.1021/ja109191z

[11] Li Z., Ma J., Cheng C., Zhang K., Wooley K. L.: Synthesis of hetero-grafted amphiphilic diblock molecular brushes and their self-assembly in aqueous medium. Macromolecules, 43, 1182-1184 (2010). https://doi.org/10.1021/ma902513n

[12] Zhang S., Zhang Q., Zhang Y., Chen Z., Watanabe M., Deng Y.: Beyond solvents and electrolytes: Ionic liquidsbased advanced functional materials. Progress in Materials Science, 77, 80-124 (2016).

https://doi.org/10.1016/j.pmatsci.2015.10.001

[13] Atkin R., Bobillier S. M. C., Warr G. G.: Propylammonium nitrate as a solvent for amphiphile self-assembly into micelles, lyotropic liquid crystals, and microemulsions. The Journal of Physical Chemistry B, 114, 1350 1360 (2010).

https://doi.org/10.1021/jp910649a

[14] Firestone M. A., Dzielawa J. A., Zapol P., Curtiss L. A., Seifert S., Dietz M. L.: Lyotropic liquid-crystalline gel formation in a room-temperature ionic liquid. Langmuir, 18, 7258-7260 (2002).

https://doi.org/10.1021/la0259499

[15] Firestone M. A., Rickert P. G., Seifert S., Dietz M. L.: Anion effects on ionogel formation in $N, N^{\prime}$-dialkylimidazolium-based ionic liquids. Inorganica Chimica Acta, 357, 3991-3998 (2004).

https://doi.org/10.1016/j.ica.2004.06.042

[16] Hoshino K., Yoshio M., Mukai T., Kishimoto K., Ohno H., Kato T.: Nanostructured ion-conductive films: Layered assembly of a side-chain liquid-crystalline polymer with an imidazolium ionic moiety. Journal of Polymer Science Part A: Polymer Chemistry, 41, 3486-3492 (2003). https://doi.org/10.1002/pola.10832

[17] Yoshio M., Mukai T., Ohno H., Kato T.: One-dimensional ion transport in self-organized columnar ionic liquids. Journal of the American Chemical Society, 126, 994-995 (2004).

https://doi.org/10.1021/ja0382516

[18] Mukai T., Yoshio M., Kato T., Yoshizawa M., Ohno H.: Anisotropic ion conduction in a unique smectic phase of self-assembled amphiphilic ionic liquids. Chemical Communications, 2005, 1333-1335 (2005).

https://doi.org/10.1039/B414631J

[19] Yoshio M., Kagata T., Hoshino K., Mukai T., Ohno H., Kato T.: One-dimensional ion-conductive polymer films: Alignment and fixation of ionic channels formed by self-organization of polymerizable columnar liquid crystals. Journal of the American Chemical Society, 128, 5570-5577 (2006). https://doi.org/10.1021/ja0606935
[20] Batra D., Daniel N. T., Firestone M. A.: Formation of a biomimetic, liquid-crystalline hydrogel by self-assembly and polymerization of an ionic liquid. Chemistry of Materials, 19, 4423-4431 (2007).

https://doi.org/10.1021/cm062992z

[21] Batra D., Seifert S., Varela L. M., Liu A. C. Y., Firestone M. A.: Solvent-mediated plasmon tuning in a gold-nanoparticle-poly(ionic liquid) composite. Advanced Functional Materials, 17, 1279-1287 (2007).

https://doi.org/10.1002/adfm.200600797

[22] Batra D., Seifert S., Firestone M. A.: The effect of cation structure on the mesophase architecture of selfassembled and polymerized imidazolium-based ionic liquids. Macromolecular Chemistry and Physics, 208, 1416-1427 (2007). https://doi.org/10.1002/macp.200700174

[23] Grubjesic S., Seifert S., Firestone M. A.: Cytoskeleton mimetic reinforcement of a self-assembled $N, N^{\prime}$-dialkylimidazolium ionic liquid monomer by copolymerization. Macromolecules, 42, 5461-5470 (2009). https://doi.org/10.1021/ma900905k

[24] Marcilla R., Blazquez J. A., Rodriguez J., Pomposo J. A., Mecerreyes D.: Tuning the solubility of polymerized ionic liquids by simple anion-exchange reactions. Journal of Polymer Science Part A: Polymer Chemistry, 42, 208-212 (2004).

https://doi.org/10.1002/pola.11015

[25] Holomb R., Martinelli A., Albinsson I., Lassègues J. C., Johansson P., Jacobsson P.: Ionic liquid structure: The conformational isomerism in 1-butyl-3-methyl-imidazolium tetrafluoroborate ([bmim] $\left.\left[\mathrm{BF}_{4}\right]\right)$. Journal of Raman Spectroscopy, 39, 793-805 (2008).

https://doi.org/10.1002/jrs.1912

[26] Seki T., Grunwaldt J-D., Baiker A.: In situ attenuated total reflection infrared spectroscopy of imidazoliumbased room-temperature ionic liquids under 'supercritical' $\mathrm{CO}_{2}$. The Journal of Physical Chemistry B, 113, 114-122 (2009). https://doi.org/10.1021/jp800424d

[27] He H., Zhong M., Adzima B., Luebke D., Nulwala H., Matyjaszewski K.: A simple and universal gel permeation chromatography technique for precise molecular weight characterization of well-defined poly(ionic liquid)s. Journal of the American Chemical Society, 135, 4227-4230 (2013). https://doi.org/10.1021/ja4012645

[28] Zheng M., Wang Z., Liu F., Mi Q., Wu J.: Study on the microstructure and rheological property of fish oil lyotropic liquid crystal. Colloids and Surfaces A: Physicochemical and Engineering Aspects, 385, 47-54 (2011). https://doi.org/10.1016/j.colsurfa.2011.05.040

[29] Nguyen H. L., Horton P. N., Hursthouse M. B., Legon A. C., Bruce D. W.: Halogen bonding: A new interaction for liquid crystal formation. Journal of the American Chemical Society, 126, 16-17 (2004). https://doi.org/10.1021/ja0369941 
[30] Imai M., Kawaguchi A., Saeki A., Nakaya K., Kato T., Ito K., Amemiya Y.: Fluctuations of lamellar structure prior to a lamella $\vec{r}$ gyroid transition in a nonionic surfactant system. Physical Review E, 62, 6865-6874 (2000).

https://doi.org/10.1103/PhysRevE.62.6865

[31] Hamley I. W., Castelletto V., Mykhaylyk O. O., Yang Z., May R. P., Lyakhova K. S., Sevink G. J. A., Zvelindovsky A. V.: Mechanism of the transition between lamellar and gyroid phases formed by a diblock copolymer in aqueous solution. Langmuir, 20, 10785-10790 (2004).

https://doi.org/10.1021/la0484927

[32] Avgeropoulos A., Dair B. J., Hadjichristidis N., Thomas E. L.: Tricontinuous double gyroid cubic phase in triblock copolymers of the ABA type. Macromolecules, 30, 5634-5642 (1997). https://doi.org/10.1021/ma970266z

[33] Liu F., Prehm M., Zeng X., Tschierske C., Ungar G.: Skeletal cubic, lamellar, and ribbon phases of bundled thermotropic bolapolyphiles. Journal of the American Chemical Society, 136, 6846-6849 (2014).

https://doi.org/10.1021/ja502410e

[34] Percebom A. M., Loh W.: Controlling the phase structures of polymer/surfactant complexes by changing macromolecular architecture and adding n-alcohols. Journal of Colloid and Interface Science, 466, 377-387 (2016). https://doi.org/10.1016/j.jcis.2015.12.050

[35] Gao X., Lu F., Shi L., Jia H., Gao H., Zheng L.: Nanostructured aqueous lithium-ion conductors formed by the self-assembly of imidazolium-type zwitterions. ACS Applied Materials and Interfaces, 5, 13312-13317 (2013). https://doi.org/10.1021/am404288x
[36] England D., Tambe N., Texter J.: Stimuli-responsive nanolatexes: Porating films. ACS Macro Letters, 1, 310314 (2012). https://doi.org/10.1021/mz2002356

[37] Yuan J., Soll S., Drechsler M., Müller A. H. E., Antonietti M.: Self-assembly of poly(ionic liquid)s: Polymerization, mesostructure formation, and directional alignment in one step. Journal of the American Chemical Society, 133, 17556-17559 (2011).

https://doi.org/10.1021/ja207080j

[38] Zhao W., Tang Y., Xi J., Kong J.: Functionalized graphene sheets with poly(ionic liquid)s and high adsorption capacity of anionic dyes. Applied Surface Science, 326, 276-284 (2015).

https://doi.org/10.1016/j.apsusc.2014.11.069

[39] de la Cruz D. S., Green M. D., Ye Y., Elabd Y. A., Long T. E., Winey K. I.: Correlating backbone-to-backbone distance to ionic conductivity in amorphous polymerized ionic liquids. Journal of Polymer Science Part B: Polymer Physics, 50, 338-346 (2012). https://doi.org/10.1002/polb.23019

[40] Fan H., Jin Z.: Freezing polystyrene- $b$-poly(2-vinylpyridine) micelle nanoparticles with different nanostructures and sizes. Soft Matter, 10, 2848-2855 (2014). https://doi.org/10.1039/C3SM53049C

[41] Xiao S., Lu X., Lu Q.: Photosensitive polymer from ionic self-assembly of azobenzene dye and poly(ionic liquid) and its alignment characteristic toward liquid crystal molecules. Macromolecules, 40, 7944-7950 (2007).

https://doi.org/10.1021/ma070972s 